\title{
"Mãe, o Que Será que o Negro Quer?” Representações Racistas na Revista Vistazo, 1957-1991*
}

Jean Rahier

\section{Resumo}

$\mathrm{O}$ artigo analisa as representações de negros na revista Vistazo, uma das mais populares publicações do Equador, desde o ano de sua criação, em 1957, até o ano de 1991. Sua tese principal é a de que a construção da identidade nacional equatoriana priva de humanidade, logo, de representatividade, dos afro-equatorianos em prol da valorização e exaltação dos euro-equatorianos e, secundariamente, dos branco-mestiços. A cosmovisão da sociedade e o ideário equatoriano de nacionalidade são interpretados pelo autor através das imagens e dos discursos sobre os negros na revista em questão. Desta forma, os afro-equatorianos são representados enquanto os "últimos Outros" no projeto das elites equatorianas de identidade nacional.

Palavras-chave: representação; afro-equatorianos; identidade nacional; mestiçagem; imaginário.

\footnotetext{
* No seminário "Entender o Racismo: O Caso do Equador" organizado pela FLACSO em novembro de 1998, no qual foi apresentada uma versão deste trabalho, um participante equatoriano branco-mestiço chegou ao ponto de repetir, em várias ocasiões, que não havia traço de racismo na imprensa equatoriana. O presente artigo demonstra quão equivocado é tal ponto de vista.
}

Estudos Afro-Asiáticos, Ano 23, no 1, 2001, pp. 5-28 
Jean Rahier

\begin{abstract}
"Mother, What Exactly Does a Negro Want?". Racial Representations in the Vistazo Magazine, 1957-1991
\end{abstract}

The article analyzes the portrayal of Negroes in the Vistazo magazine, one of Ecuador's most popular publications since its inception in 1957 until 1991, year of its discontinuity. Its main thesis is that the national Ecuadorian identity deprives Afro-Ecuadorians of humanity, ergo, of representation, in favor of the valorization and exaltation of Euro-Ecuadorians, followed in second place by White-Mestizos. The author interprets the cosmovision of society and the Ecuadorian outlook on nationality through imagery and discussions on Negroes in above mentioned magazine. Thus, Afro-Ecuadorians are represented as the "ultimate Others" in the scheme of the national identity of the Ecuadorian elite.

Keywords: representation; Afro-Ecuadorians; national identity; miscegenation; imaginary.

\title{
Résumé
}

"Mère, qu'est-ce que le Noir peut bien vouloir?" Représentations racistes dans la revue Vistazo, 1957-1991

Dans cet article, on souligne les représentations sur les Noirs relevées dans la revue Vistazo, l'un des périodiques les plus populaires de l'Équateur, depuis sa fondation en 1957 jusqu'en 1991. L'auteur veut montrer que la construction de l'identité nationale équatorienne tend à priver d'humanité et du coup, de représentativité, les Afro-équatoriens au profit de la valorisation et de l'apologie des Euro-équatoriens et, en second lieu, des Blancs-métis. La cosmovision de la société et la façon qu'ont les Équatoriens d'envisager la nationalité sont interprétées à travers les images et les discours sur les Noirs de la revue en question. Ainsi, les Afro-équatoriens sont représentés comme les "derniers Autres" dans le propos des élites équatoriennes concernant l'identité nationale.

Mots-clé: représentation; Afro-équatoriens; identité nationale; métissage; imaginaire.

Estudos Afro-Asiáticos, Ano 23, no 1, 2001, pp. 6-28 
$\mathrm{N}$ ão há mundo que exista independentemente dos discursos de representações. Estas constituem, em parte, o mundo no qual vivemos. Como explicou Michel Foucault já faz algum tempo, as formaçóes discursivas - ou modos de pensar, ou modos de representações - são utilizadas pelas pessoas para pensar o mundo, para pensar suas próprias existências, assim como para pensar a existência de Outros. Os grupos dominantes produzem e reproduzem representações de si mesmos e representações dos Outros, que justificam sua posição no cume das ordens raciais e espaciais, e a exploração dos Outros, que aparecem como seres fundamentalmente negativos. De fato, como formula o intelectual inglês negro Stuart Hall, o racismo deve ser entendido como uma "estrutura de conhecimento e representações", 'com uma energia simbólica e narrativa que trabalha para assegurar nossa posição aqui, em cima, assim como para assegurar que os Outros permaneçam lá embaixo, fixando cada um "em seu lugar social 'natural" (Hall, 1992). Esta é a razão pela qual um aspecto importante da luta dos povos dominados consistiu em questionar, manipular, combater, negar e, às vezes, até inverter representaçóes deles reproduzidas no discurso dominante de sua sociedade nacional, ou da sociedade em que vivem.

As identidades culturais e/ou étnicas e/ou "raciais" devem ser entendidas dentro dos sempre flutuantes processos políticos, econômicos e sociais inscritos em contextos espaço-temporais particulares, que são constituídos dentro de dimensões locais, regionais, nacionais e transnacionais. As identidades e suas representações são constantemente imaginadas e re-imaginadas, atuadas e reatuadas dentro de situaçóes específicas, e dentro de contextos socioeconômicos e políticos que sempre mudam e que fornecem lugares para suas negociações e renegociações, suas definições e redefinições.

Não foi por acaso que me referi, acima, a Stuart Hall. Ele é considerado um dos fundadores do movimento dos Cultural Studies, ou "Estudos Culturais", na Inglaterra. Os intelectuais que participam desse movimento dedicaram uma parte importante de

Estudos Afro-Asiáticos, Ano 23, no 1, 2001, pp. 7-28 
suas pesquisas ao estudo do racismo e de suas várias formas e expressões em "culturas populares" no mundo inteiro. Evidenciaram a maneira como o racismo mostra sua cara feia nos lugares mais surpreendentes, onde "ninguém" o teria esperado, e onde alguns - habitualmente os que não sofrem suas conseqüências - até proclamam que não está...

No presente artigo, minha atenção concentra-se nas representações de pessoas negras na revista Vistazo, desde sua criação, em 1957, até 1991. ${ }^{3}$ Passei horas procurando representaçóes de negros em Vistazo, página por página, tirando slides e copiando artigos e fotos. A focalização desta pesquisa em Vistazo justifica-se pelo fato de tratar-se da revista mais popular do Equador. Vistazo, assim como outros meios de comunicação, proporciona aos grupos dominantes um espaço privilegiado onde expressar sua cosmovisão, ou o que se poderia chamar de uma versão oficial do chamado "senso comum nacional". Qualquer pessoa que já teve nas mãos um número de Vistazo pode perceber que o que a revista vende a seus leitores não é senão o olhar branco, ou branco-mestiço, sobre os vários povos do Equador e do mundo. Obviamente, as representações de negros publicadas em Vistazo são produzidas a partir de uma posição elitista, masculina, branca ou branco-mestiça, e de uma perspectiva urbana. O "nós" do Vistazo não é um "nós" que inclua as subjetividades negras e indígenas, nem as perspectivas das populações rurais. Ao contrário.

As representações de negros em Vistazo mostram que o conceito de "negro" que as elites equatorianas têm não é monolítico. Embora seja quase sempre negativo, ou às vezes agressivamente racista, a maneira como essas elites compreendem o negro, ou dele se aproximam, está enraizada em termos contraditórios: repulsa, mas também desejo; medo extremo, mas também atração etc. Estas contradições explicam a presença, em diferentes períodos, e em diferentes números, de imagens antitéticas, como a do gentil cantor, do músico ou desportista, e a do predador social ou criminoso; a imagem do(a) possível amante exótico(a) e a do sujo doméstico preguiçoso etc. Antes de compartilhar os avanços da minha pesquisa, preciso primeiro explicar o que entendo pelo conceito de "ordem racial/espacial".

\section{A Ordem "Racial”/Espacial Equatoriana}

Desde o início da vida republicana do país, assim como ocorreu em outros países latino-americanos, a elite branca e bran-

Estudos Afro-Asiáticos, Ano 23, no 1, 2001, pp. 8-28 
co-mestiça reproduziu uma "ideologia equatoriana" de identidade nacional, que proclama o mestiço como protótipo da cidadania moderna equatoriana (Clark, 1998a, 1998b; Rahier, 1998; ver, também, Anderson, 1991; Arocha, 1998; Gould, 1993; McCallum, 1996; Needell, 1995; Pérez-Torres, 1998; Radcliffe, 1996). Essa ideologia baseia-se em uma crença na inferioridade da população indígena e em uma incondicional, às vezes contraditória, admiração e identificação com o que chamam de "a civilização ocidental” (Silva, 1995; Stutzman, 1981; Whitten, 1981).

Apesar da tentativa hegemônica de homogeneização racial e étnica, esta ideologia equatoriana de identidade nacional tem como resultado uma leitura racista do mapa do território nacional. Os centros urbanos são associados à modernidade e à população branca e branco-mestiça, e as áreas rurais são vistas como lugares caracterizados por inferioridade racial, violência, atraso de todo tipo, selvageria etc. Essas áreas, majoritariamente habitadas por não-brancos, ou não-branco-mestiços, foram vistas por essas elites como imensos desafios para o desenvolvimento nacional rumo aos ideais da modernidade. Desta maneira, o Equador tem características comuns com a Colômbia, como colocou Peter Wade em seu livro Blackness and Race Mixture: "há um distintivo padrão espacial na estrutura [...] da nação e de sua ordem racial" (Wade, 1993; ver, também, Ching, 1997; Feld, 1996; Ferguson, 1992; Gupta, 1992; Malkki, 1992).

Nesta imaginação da equatorianeidade, não há, logicamente, nenhum lugar para os negros: eles são, e devem permanecer, marginais. Eles constituem o último Outro, uma espécie de aberração histórica, um ruído dentro do sistema ideológico da nacionalidade, uma contaminação do patrimônio genético equatoriano. Não fazem parte dessa "mestiçagem oficial" (Stutzmam, 1981:63).

\section{Representações da Identidade Nacional em Vistazo}

Vistazo publicou uma série de artigos, fotografias, imagens e outras representações que ilustram a "ideologia oficial” de identidade nacional. Várias publicidades, por exemplo, codificam a visão que as elites têm da "equatorianeidade". Estas publicidades são caracterizadas por uma ausência da população negra. Têm como tema dominante a mestiçagem, que é apresentada como a essência mesma da "equatorianeidade". E, quando fazem referência aos in- 
dígenas, é como indivíduos que aparecem apenas como vestígios do passado: devem ser modificados, "civilizados", "branqueados" (cf. Muratorio, 1994).

Esta idéia, segundo a qual os povos indígenas representam apenas o passado nacional, é um tema de muito interesse para os redatores de Vistazo. Um desses artigos é intitulado "Sondando o passado do homem equatoriano" (24/11/1978). Enfoca investigações arqueológicas conduzidas por pesquisadores do Banco Central do Equador da Sucursal de Guayaquil, e vem acompanhado de uma fotografia que mostra algumas moças chachis da Província de Esmeraldas, de pé, com os seios nus, vestindo trajes tradicionais (da cintura para baixo). Abaixo da fotografia lê-se a seguinte legenda: "Estas belas mocinhas são cayapas, da província de Esmeraldas. Mantêm características que o tempo respeitou" (:27). O artigo pula do passado arqueológico ao presente tradicional como se fosse a mesma coisa. Legendas como esta apontam para a contínua influência de teses evolucionistas do século XIX (Darwin, Tylor e outros) sobre o "senso comum" branco-mestiço. Outro artigo, intitulado "Tribos condenadas à morte" (15/3/1985:36-41), explica a "degeneração" de povos indígenas, que não puderam adaptar-se à civilização pelo fato de "ainda serem vítimas de velhas tradições malsãs" que os levarão à morte. Uma frase diz: "Os waoranis têm uma população com alto grau de anormalidades por causa do casamento endogâmico entre pais, filhos e irmãos" (:41).

Outro artigo obviamente paternalista, que apresenta os resultados de uma pesquisa conduzida por um psiquiatra na Província de Cotopaxi, proclama uma grande descoberta de 1972: "Realmente há inteligência superior no índio" (1/1972:100-102). Esta descoberta dá mais valor à mestiçagem porque limita, ou, antes, corrige, a "contribuição negativa" do ingrediente indígena...

Estas representações de indígenas são marcadas pelo contraste que estabelecem - em uma perspectiva branco-mestiça dominante - com as imagens de pessoas brancas nacionais, americanas e européias. Ao contrário daquelas, estas evocam seres civilizados, modernos e respeitáveis. As características de seus corpos definem o que se considera belo, atraente, desejável, ilustrando a ideologia do branqueamento tal como é argumentada por Normam Whitten: "branqueamento" não quer dizer que o branco se "indianiza” e sim, ao contrário, que é o índio que deve se branquear cultural e fisicamente.

Quanto aos negros, não fazem parte da química nacionalista. Nem são considerados como um dos ingredientes da mestiça-

Estudos Afro-Asiáticos, Ano 23, no 1, 2001, pp. 10-28 
gem oficial. Em vez de serem simplesmente invisíveis, como tantas vezes se argumentou no passado, são, antes, construídos ideologicamente, através de suas representações, como os "últimos Outros".

\section{Os Negros como Últimos Outros}

No passado, argumentou-se que, no Equador e em outros países latino-americanos com proporções demográficas semelhantes, os negros eram simplesmente invisíveis ou totalmente ausentes dos imaginários branco e branco-mestiços das identidades nacionais. Em parte, este argumento é resultado da falta de interesse pelos negros, que caracterizou as pesquisas em Ciências Sociais e nas Humanidades equatorianas. Nina de Friedemann demonstrou a existência dessa falta de interesse por tudo que se referia ao negro no caso da Colômbia (Friedemann, 1984). Por outro lado, o argumento sobre a "invisibilidade do negro" está inscrito em uma tradição relativamente longa de pesquisa sobre os Estados-nação e as nacionalidades modernas. De fato, muitos pesquisadores que estudaram o surgimento dos nacionalismos e dos Estados-nação do final do século XVIII e no século XIX, têm em comum a tendência a concentrar sua atenção exclusivamente no que chamaram de "processos homogeneizadores" das ideologias que estão por trás das nacionalidades modernas. É precisamente o que faz, por exemplo, Benedict Anderson em seu famoso Imagined Communities (1991[1983]:47-66). Também é o caso de Stuart Hall, ao escrever que as "culturas nacionais" ajudam a "costurar" as diferenças dentro de uma identidade singular. Embora a tendência homogeneizadora das ideologias de identidade nacional seja bem concreta e possa ser observada em vários lugares do mundo, e não apenas no Equador, essas ideologias de identidade nacional também estão marcadas por outro fenômeno que aparece, após uma primeira leitura superficial, como contraditório a esta ambição homogeneizadora. Poderíamos referir-nos a esse fenômeno como a necessidade de construir um Outro, os Outros. Vários pesquisadores preferiram focalizar sua atenção sobre esta necessidade que têm os mitos constituintes das ideologias de identidade nacional de criar um Outro. A premissa desses autores é a seguinte: as identidades jamais existem por si mesmas, sozinhas. As identidades existem por oposição, ou seja, sua natureza profunda, ou sua condição de existência, é estarem opostas a outras identidades, dentro do espaço

Estudos Afro-Asiáticos, Ano 23, no 1, 2001, pp. 11-28 
Jean Rahier

nacional e fora dele. Sem esta oposição, não haveria necessidade de ter nenhuma identidade. $\mathrm{Na}$ década de 1960 , pesquisadores que trabalhavam sobre o surgimento de nacionalidades, como Ernest Gellner (1964; 1983) ou Karl Deutsch (1966), e, mais tarde, pessoas como Anthony Smith (1986), Walker Connor $(1978,1993)$, Elie Kedourie (1992) e Anna Triandafyllidou (1998), já estavam trabalhando com esse conceito. Mais recentemente, um desses pesquisadores, Talal Asad, antropólogo do Oriente Médio que vive nos EUA, desenvolveu a seguinte argumentação:

[...] para assegurar a sua unidade - para fazer sua própria história - os poderes dominantes sempre trabalharam melhor com práticas que diferenciam e classificam [...]. Neste contexto, o poder é construtivo e não tanto repressivo. Além disto, sua capacidade de selecionar ou construir as diferenças que servem a seus propósitos dependia da exploração dos perigos e das oportunidades que as situaçôes ambíguas contêm (Asad, 1993:17).

Peter Wade, em seu estudo sobre a incorporação de formas musicais afro-colombianas aos gêneros da "música nacional colombiana", segue o mesmo argumento (ver, também, Moore, 1997):

[...] a diversidade é necessária às idéias nacionalistas, em parte porque é apenas em relação à diversidade que a unidade pode ser imaginada, mas também porque a diversidade quase sempre envolve relaçóes de poder.

Assim como nas relações de poder colonial o colonizador tem um senso de dominação que é nutrido por um desejo narcisista de subjugar o subordinado Outro, os construtores de nações definem sua própria superioridade em relação à diversidade que observam e constroem - e desejam. Distinção como excelência depende de distinção como diferenciação; discriminação como refinamento e gosto superior depende de discriminação contra as pessoas definidas como inferiores e diferentes (Wade, 1998:4).

As construções de indígenas aparecem de maneira muito visível em comparação com as construções de negros nos mitos de equatorianeidade, desde o início da vida republicana. Os afro-equatorianos sempre ocuparam um lugar periférico. Sua visibilidade marginal dentro desses mitos não pode ser comparada com a relativa centralidade dos grupos indígenas. Nas narrativas brancas e branco-mestiças sobre a identidade nacional, nas produções artísticas sobre costumes e em outras representações, os indígenas foram construídos, como demonstrou admiravelmente Branca Muratorio, como descendentes dos nobres incaicos, como

Estudos Afro-Asiáticos, Ano 23, no 1, 2001, pp. 12-28 
os selvagens do Oriente ou jívaros, ou como pagãos que requeriam o trabalho das missões evangelizadoras e civilizadoras (Muratorio, 1994). Mas, aparecem claramente como um dos mais importantes componentes ou ingredientes da identidade mestiça ou branco-mestiça nacional (conforme o período histórico), mesmo especificando-se que têm de ser modificados, evangelizados, civilizados e branqueados. A leitura de textos escritos por intelectuais equatorianos brancos e branco-mestiços evidencia a construção do negro como "último Outro". Refiro-me aqui, principalmente, a textos escritos, no início do século XX, por Alfredo Pérez Guerrero, Victor Gabriel Garcés, Julio Moreno, Humberto García Ortiz, Manuel José Caicedo, Gabriel Cevallos García, Leopoldo Benítez Vinueza etc. ${ }^{5} \mathrm{O}$ caráter periférico do negro manifesta-se principalmente das seguintes maneiras: habitualmente, nos textos destinados a desenvolver idéias e comentários sobre o estado da cultura, e/ou identidade e/ou história nacional, as referências aos afro-equatorianos são muito escassas e breves. Até agora, nunca vi essas limitadas referências sugerirem que eles fossem equatorianos ou, se não são pensados como cidadãos como os indígenas, ao contrário destes não são incluídos no grupo dos que poderiam tornar-se cidadãos depois de um processo de "inculturação" ou de "civilização"... Os termos utilizados para referir-se a eles - "africanos", "raça negra", "negros" ou "morenos" - jamais são precedidos - como no caso dos "índios", "raça índia" ou "indígenas" - do possessivo paternalista "nosso(s)", o que os situa clara e definitivamente fora do projeto de identidade nacional. Além disto, quando se faz referência à existência de negros dentro do território nacional, isto ocorre nas partes mais descritivas dos textos, sem voltar a eles, nem à sua presença ao escrever-se sobre a solução a ser dada aos "problemas raciais e culturais do país" (o famoso "problema índio" ou "problema indígena"). Segundo esses intelectuais brancos e branco-mestiços, a solução do "problema racial e cultural do país" só envolve os índios, jamais inclui os negros - sabemos que estão ali, mas têm de ficar de "fora", e nem são concebidos como "problema" que afeta a questão nacional... Eis alguns exemplos. Em um texto intitulado "La misa de las lanzas", Leopoldo Benítez Vinueza escreve, em 1950, sobre os acontecimentos de 6 de março de 1845 , que ele chama de "início da vida autenticamente nacional", e diz:

Durou quinze anos a tutela providencial do Caudilho. Quinze anos de sangue e lágrimas em que só se ouviu, entre um povo apavorado, o golpe

Estudos Afro-Asiáticos, Ano 23, no 1, 2001, pp. 13-28 
Jean Rahier

dos cascos das cavalhadas e o ruído metálico dos sabres. Quinze anos em que passearam por um país desesperado as lanças estrangeiras, os bárbaros fardados, as feras com galóes cujo exemplar mais representativo e arrogante era o general negro Juan Otamendi. (Benítez Vinueza, 1950:201)

A última frase refere-se, com a força de último argumento retórico da lista de calamidades, ao antagonismo de um negro vestido de general... Em um texto publicado em 1922, Alfredo Pérez Guerrero escreve sobre a história e a cultura nacionais em estilo positivista, fazendo muito poucas referências aos negros ou à "raça negra”. Em uma passagem, caracterizada pelo determinismo geográfico, menciona os negros uma única vez - como uma força de trabalho maleável. Escreve que:

[...] o meio e a vida são círculos máximos que circunscrevem as forças sociais: em outros termos, indicam o que não pode ser, mas não o que será. Esta mera circunstância é importantíssima; se, por exemplo, sabemos que um país montanhoso se prestará menos para o comércio do que outro que está ao lado dos mares e rios, esse povo deveria fazer menos esforços para se dedicar ao comércio do que à agricultura; se sabemos que a raça negra suporta facilmente os climas ardentes, não a dedicaremos a cultivos de climas frios etc. (Pérez Guerrero, 1922:142)

A seguir, depois de indicar que o seu desejo é melhorar o Equador, continua escrevendo sobre o "problema índio", precisando que "[me] circunscreverei à Raça Índia por ser esta um dos problemas a que estão enlaçados os principais entraves ao avanço que temos; e porque acredito que, depois do problema dos limites com o Peru, este é o mais grave e palpitante" (ibidem: 143). Os negros nem são incluídos como problema. Outro intelectual branco-mestiço, Víctor Gabriel Garcés, em artigo sobre as nacionalidades americanas publicado nos Anais da Universidade Central de Quito em 1933, é muito mais eloqüente a respeito da presença de negros. Nesse texto, Garcés termina festejando a mestiçagem como uma das conseqüências primordiais da conquista. Escreve que "índios, brancos e negros são os matizes primários da população continental”, antes de passar em revista cada um desses elementos raciais. Sobre os negros, indica:

O negro africano, material humano cotável em longa etapa da civilização, também deveria ter vindo à América, mercado sem concorrência para as empresas exportadoras do "mogno" vivo [...]. As necessidades industriais de aproveitamento da rara energia do homem de cor, avezado, fisiologicamente adaptado aos climas tropicais enervantes, exigiram e determinaram a demanda daquela mercadoria necessária. E até as colô-

Estudos Afro-Asiáticos, Ano 23, no 1, 2001, pp. 14-28 
Mãe, o Que Será que o Negro Quer?

nias louras do Norte, com o reparo puritano de seu contexto étnico, tiveram de admitir o negro robusto e alegre, risonho apesar de suas nostalgias ancestrais, para dedicá-lo à indispensável tarefa, nas zonas adequadas para o negro, porém insuportáveis para o inglês da América. Por todas as veredas da América Hispânica onde o clima solicitava o negro, estendeu-se esta contribuição racial trazida do fundo inesgotável da África Equatorial. (Garcés, 1986 [1933]:104)

A seguir, Garcés justifica a dominação do espanhol sobre o índio e o negro nos seguintes termos:

O espanhol, conquistador, e depois fazendeiro, industrial, comerciante, homem de mundo, homem de cultura, tinha que superar o índio e o negro. O índio, porque se impôs sobre ele e o atemorizou e subjugou. O negro, porque, apesar de sua altivez característica, não tem suficiente sentimento de classe, de grupo, que dá vigor formal à coletividade em que se vive. O espanhol era muito mais apto a aproveitar imediatamente sua energia, tanto individual como social. E era precisamente ele que havia de formar a hierarquia dominadora no viver coletivo dos povos da América. Nos campos político, social, econômico, em todas as esferas de atividade, o branco em primeiro lugar. $\mathrm{O}$ índio, superior em número, recuou para as quebradas andinas, ou embrenhou-se na imensidão virgem da selva. O negro, que chegou por último, não era estorvo maior porque vivia confinado a determinadas áreas territoriais. Portanto, o branco assenhoreou-se de seus domínios. (ibidem:107)

No resto de seu artigo, durante quase vinte páginas, Garcés tendo o Equador em mente - trata do tema da mestiçagem, e o negro esfuma-se como em um passe de mágica. Claramente, o negro não faz parte dessa imaginação das nacionalidades americanas ideais, na perspectiva branca ou branco-mestiça de Garcés. Ao contrário, Garcés lança-se na outra direção, em um caminho que aponta a Europa como modelo biológico e cultural, citando os países do Cone Sul, onde houve uma imigração mais numerosa de europeus, o que explica o estado mais avançado dessas naçóes. Garcés imagina um processo de branqueamento dos índios, mas não dos negros, que continuam "confinados a determinadas áreas territoriais", ou seja, "fora".

Os demais autores consultados, que escreveram em vários períodos da história do país, dividem-se entre as seguintes tendências: 1 . Referir-se aos negros só de passagem, registrando sua presença periférica, ou antes; 2 . fazendo referências diretas a eles para depois, quando se trata de comentar ou elaborar sobre o futuro da "identidade, cultura e história equatorianas", esquecê-los onde é "seu lugar": nas margens (frontier areas).

Estudos Afro-Asiáticos, Ano 23, no 1, 2001, pp. 15-28 
Jean Rahier

Parece-me interessante frisar aqui o paralelo entre esta marginalidade - ou condição de último Outro - do negro nos processos imaginativos de intelectuais brancos e branco-mestiços de final do século XIX e começo do XX, e a mesma marginalidade dos negros nas pesquisas acadêmicas equatorianas. Esta última contrasta fantasticamente com a abundância de pesquisas sobre populaçōes indígenas. Apresentarei aqui duas breves ilustrações, com textos escritos por pesquisadores que, apesar do presente comentário, respeito muito. Em Los mitos de la ecuatorianidad (Silva, 1995), Erika Silva nunca menciona a existência de negros dentro do território equatoriano. Além disto, ignora a questão e a significação de sua invisibilidade nesses mitos da "identidade equatoriana". Em um artigo intitulado "La cuestión de las identidades en Quito" (Ibarra, 1995), Hernán Ibarra trata da história de Quito na perspectiva dos processos de identidade de suas populações, em termos das categorias étnicas de "brancos", "branco-mestiços", "indígenas", "cholos" etc. Através de uma análise muito interessante de sucessivas modas musicais, da história do itinerário das festas de Quito, bem como de vários textos literários, procura descrever o desenvolvimento histórico da problemática das identidades em Quito. Mas, sobre os negros não escreve uma só palavra, apesar de uma documentada presença negra desde o início da fundação espanhola de Quito e de uma imigração negra relativamente importante durante os últimos vinte anos, o que levou ao surgimento de uma significativa população quitenha negra (Whittem, 1995).

Infelizmente, muitas das publicações que enfocam temas afro-equatorianistas tendem a representar os afro-chotenhos e os afro-esmeraldenhos em termos essencialistas e exclusivamente como comunidades fundamentalmente rurais, localizadas na periferia do espaço nacional, que existiram de certa maneira à margem da vida moderna. Essas representações das realidades socioculturais dos negros, com invisibilidade ou presença essencializada, além de serem incompletas e enganosas, não fazem senão reproduzir e reforçar o que chamo de ordem "racial"/espacial equatoriana.

Voltando à Vistazo, reúno as várias representações de negros em quatro categorias. Na verdade, essas categorias também foram utilizadas - conscientemente ou não - pelos jornalistas e editores de Vistazo: 1 . os africanos; 2. os negros equatorianos; 3. os negros norte-americanos; 4. o resto da diáspora africana nas Américas. Estas representaçôes divulgam a lógica da ordem "racial”/espacial equatoriana, bem como a visão que as elites nacionais têm do resto

Estudos Afro-Asiáticos, Ano 23, no 1, 2001, pp. 16-28 
do mundo e de sua suposta hierarquia cultural. Assim, pode-se observar em Vistazo que a Europa e a América do Norte encontram-se no alto da escala de "respeitabilidade cultural" compartilhada pelas várias equipes de redação, ao passo que a África, ao contrário, jaz a seus pés. Esta escala de "respeitabilidade cultural" tem condições de existência, e/ou influências transnacionais.

\section{Caráter Negativo do que se Refere ao Negro (em Geral) em Vistazo}

Várias representações de tudo que se refere ao negro nas páginas de Vistazo não têm especificações étnicas precisas. Não mencionam negros em particular, como afro-esmeraldenhos, afro-chotenhos, afro-brasileiros, yorubás etc. Estas imagens funcionam simplesmente como se estivessem pedindo ao leitor que se lembre do significante "negro" que está profundamente enterrado no inconsciente coletivo (branco e branco-mestiço) equatoriano e, para além dele, no inconsciente coletivo Ocidental. São imagens fundamentalmente estereotipadas e altamente negativas.

Algumas aparecem sob a forma de piadas. Uma delas, por exemplo, caracteriza os negros como seres estúpidos. Representa um casal de negros que se encontra no escuro. Pode-se adivinhar que são negros pelos estereótipos dos traços de seus rostos: grandes olhos brancos, grandes dentes, lábios enormes. O homem diz à mulher: "Cortaram a luz! Por fim poderemos fazer nossa poupança!” (no 66, 11/1962:98). Outra piada representa cinco negros vestidos apenas com um lenço ao redor da cintura. Estão sentados em torno de uma mesa na qual se encontra um homem branco, sendo cozido... Um dos negros tem uma Bíblia nas mãos e diz: "Obrigado, Senhor, por ter-nos permitido trazer a esta mesa... o pão de cada dia. Amém” (no 82, 7/1972:138). Em outra piada, o negro evoca a farra descontrolada, a preguiça, a sensualidade "natural", os ritmos musicais etc. Um homem branco, que está na praia com sua esposa, levanta-se e diz, rodeado por negros com chapéus de palha e instrumentos musicais: "Inês! Não sei o que você há de pensar, mas eu não volto para casa..." (n ${ }^{\circ} 125$, 10/1967:138), como se tivesse decidido trocar o stress da vida moderna pela vida fácil dos negros que sabem gozar a vida.

Outras representações de negros sem indicações étnicas são feitas em artigos que têm o objetivo de tratar da humanidade de maneira relativamente abstrata, em um âmbito geográfico global. 
Um desses, intitulado "Morte prematura da humanidade" (10/1974:53), discute a tese de Malthus e evoca os negros como um problema social permanente: não sabem como cuidar-se; sempre necessitam ajuda de algum tipo; fazem filhos como coelhos etc. Em poucas palavras, não nos - este é um "nós" branco ou branco-mestiço, é claro - deixam em paz... O conteúdo do artigo poderia ser resumido à seguinte citação, que foi publicada abaixo do subtítulo "Quem perecerá primeiro?": "Nesta morte coletiva, avançando inexorável, inicialmente perecerão as pessoas de poucos recursos, os lares pobres. Morrerão primeiro as maiorias despossuídas...". A fotografia que acompanha o artigo apresenta um menino negro, magérrimo, com a mão direita estendida como para pedir esmola...

Outro artigo, intitulado "Desaparecerá a raça branca?" (6/6/1978:82-84), contradiz a argumentação do artigo anterior. Sugere que, dentro de poucas décadas, as raças negra e amarela dominarão a população mundial. Comentando dados demográficos e também as crises do petróleo da época (final da década de 1970), o jornalista escreve:

Por conseguinte, é possível prever, com elevado nível de certeza, que a crise atual e próxima da energia terá não apenas um efeito sobre a civilização industrial, mas também sobre a distribuição das populaçôes e das raças humanas. A espécie humana mudará de cor. Os brancos, que jamais estiveram em maioria, tornar-se-ão uma pequena, e depois muito pequena, minoria... A espécie humana mudará de pele.

Depois, no mesmo artigo, o jornalista acrescenta com grande otimismo - utilizando o termo obviamente negativo de "inflação": "Mas a proporção das populações e das raças estará finalmente - após uma fase de inflação amarela, ou morena, ou negra - próxima à proporção atual". Estas poucas referências foram escolhidas entre numerosas outras. Elas anunciam os maiores temas que são repetidos e "tecidos" dentro das representações de negros das quatro categorias com as que estou trabalhando.

\section{Representações da África e de Africanos}

A África é, definitivamente, um lugar firmemente marcado como negativo nas páginas de Vistazo. É um lugar onde há desordem política e golpes de Estado. É um lugar onde existe um número impressionante de tiranos. A África de Vistazo parece um Continente onde os líderes políticos, muito mais que em qualquer outra

Estudos Afro-Asiáticos, Ano 23, no 1, 2001, pp. 18-28 
parte, portanto, muito mais do que na América Latina, não têm nenhuma consideração por seus povos. É um lugar onde, para usar o vocabulário evolucionista de Vistazo, a vida selvagem e os cultos estranhos ainda ocorrem. É um lugar açoitado pela fome e outras numerosas calamidades. Em poucas palavras, a África de Vistazo é caracterizada pela irresponsabilidade: os africanos não são nada além de crianças imaturas.

Quanto ao período que vai de 1957 a 1991, não encontrei um só artigo que apresentasse a África de maneira positiva. Dos 61 artigos sobre a África publicados entre 1957 e 1991, mais de cinqüenta são sobre algum tipo de desordem política: guerra de independência, golpes de Estado, excessos de pequenos tiranos, massacres políticos etc. Um desses artigos, publicado no número de janeiro de 1965, relata a guerra civil na República do Congo-Leopoldville. O jornalista escreve:

Uma luta selvagem desenrolou-se nas ruas da bela cidade [colonial], tropas do governo legal avançavam pelas desertas avenidas semeadas de mortos, moscas e carros virados, guerreiros semi-selvagens de Soumialot [o líder rebelde], entoando cantos rituais e fórmulas de magia negra, lançaram-se ao contra-ataque apoiados por abundantes rajadas de metralhadoras e fuzis automáticos chineses.

É preciso enfatizar aqui o fato de que só os rebeldes são "racializados". Além disto, o jornalista refere-se a eles com todos os adjetivos (negativos) atribuídos a tudo que é "negro" ou "africano": "guerreiros", não "soldados"; "semi-selvagens", e "magia negra". Adicionalmente, a origem dos fuzis automáticos também é satanizada: são fuzis "chineses", o que era muito ruim naqueles tempos de Guerra Fria... Não é possível entrar aqui nos detalhes desta guerra civil. Mas já se pode indicar que os soldados do chamado "governo legal" (na verdade, era um governo de títeres manipulado por vários governos ocidentais, em um contexto claramente neocolonialista) talvez não estivessem lutando ao lado do "bem", como sugere o jornalista.

Antes de meados da década de 1960, não houve reportagens sobre a África. Depois dessa data, sua presença limitada na revista é marcada por catástrofes. Uma variedade de artigos, da segunda metade dos anos 1960 até os anos 1980, referem-se à sangrenta secessão da região de Biafra, na Nigéria; às atrocidades do ditador Idi Amim Dada - que teve grande visibilidade nos números de Vistazo da década de $1970^{6}$; às "palhaçadas" de outro ditador, o Marechal Bokassa, da República Centro-Africana etc. Muitas das expressões

Estudos Afro-Asiáticos, Ano 23, no 1, 2001, pp. 19-28 
utilizadas pelos jornalistas que relatam esses acontecimentos trazem suas interpretaçōes racistas e essencialistas. "A África Ruge", diz o título de um artigo sobre um massacre político na Rodésia (hoje Zimbábue): em vez de culpar os autores do fato lamentável, culpam a chamada "raça africana" inteira... "África: coração da AIDS” (27/3/1987:60) diz outro, sugerindo, de certa maneira, que esses negros selvagens e africanos são responsáveis por este novo mal etc.

Em um artigo sobre a África do Sul (2/1981:58-63), os negros africanos são identificados como gente tradicional, atrasada e exótica, ao passo que os brancos sul-africanos, ao contrário, são claramente associados à modernidade, à vida urbana, aos edifícios altos, à civilização etc. Neste artigo, mulheres negras africanas são apresentadas com os seios nus, de pé ou de quatro, em uma página, enquanto em outra página do mesmo artigo está a fotografia de uma mulher branca, da qual só se vê o rosto: está de óculos e olha para o céu. $\mathrm{O}$ fato de divulgar ou esconder o corpo feminino tem muito a ver com a distinção - muito importante na América Latina - entre os conceitos de "mulher" (usualmente de pele mais escura ou negra, associada à vulgaridade, falta de educação, de acesso sexual fácil etc.), por um lado, e, por outro, de "senhora" (branca ou de pele mais clara, respeitável, casada, culta etc.) (ver, também, Melhuus, 1996). Neste sentido, um artigo de 1973 (no 194:80-82) apresenta bailarinas africanas, do Senegal, com o busto descoberto. Um subtítulo do artigo diz "Ninguém criticou o fato de as bailarinas se apresentarem com o busto descoberto". As fotografias foram tiradas durante uma turnê que o balé nacional do Senegal fez em Guayaquil. Naquela época, nenhum corpo de mulher branca ainda tinha sido exposto dessa maneira em Vistazo...

\section{Representaçóes de Afro-Equatorianos}

Uma das constantes mais importantes nos artigos de Vistazo com representações de pessoas afro-equatorianas é, sem dúvida, a diferença no tom do jornalista quando fala - nos textos escritos e/ou através do material visual - sobre negros da zona rural (as Províncias de Esmeraldas, Imbabura, Carchi e, mais particularmente, o Vale do Chota) e negros da zona urbana (principalmente Guayaquil e Quito). Os negros aparecem como fora do seu lugar "natural" em área urbana, onde são fundamentalmente interpretados como predadores sociais. São associados a crimes de todo tipo, de-

Estudos Afro-Asiáticos, Ano 23, no 1, 2001, pp. 20-28 
pendência de drogas, estupro etc. Em áreas rurais, ao contrário, os negros são representados como associados a formas musicais exóticas, à marimba, e a outras tradiçôes culturais inofensivas, embora estranhas. Os negros rurais são representados como se estivessem vivendo em seu local reserva, como que mais próximo à natureza, $\mathrm{o}$ seu "lugar social natural", como diz Stuart Hall. Muitas vezes são vistos como vítimas de catástrofes naturais e outros problemas de saúde. Imagens de negros equatorianos simplesmente positivas são muito raras na história de Vistazo. Em alguns casos limitados, aparecem na revista como heróis nacionais e atletas que ganham medalhas e outros títulos durante eventos esportivos internacionais. A maior figura que cumpriu esse papel foi, com certeza, Alberto Spencer, nas décadas de 1950 e 1960. Mais tarde, vê-se Lupo Quiñonez, Liliana Chalá e inúmeros outros. A menção a esportistas afro-equatorianos sempre está acompanhada do uso de um adjetivo como "negro", "moreno", "de ébano" etc. Isto denota o mal-estar dos jornalistas brancos e branco-mestiços, assim como dos editores da revista, para quem é impossível não "racializar" um indivíduo negro quando aparece em uma fotografia, como se a cor de sua pele não pudesse deixar de ser mencionada. É claro que esportistas que não são negros jamais são "racializados": a cor de sua pele é considerada "normal"... Assim, temos menções como, para Liliana Chalá, "A negra de ouro" (19/12/1986:87-88); "o negro Ítalo Estupiñan" que também é chamado de "o gato selvagem"... (7/4/1978:92-95); ou, em outro registro, "o chinês negro", para referir-se a Jaime Hurtado...

Imagens negativas de afro-equatorianos referem-se mais a homens do que a mulheres. As imagens de mulheres afroequatorianas costumam estar associadas a algum aspecto "menos negativo", mesmo se ele consiste na manipulação delas e de seus corpos como uma encarnação do mito da Vênus negra, objeto sexual por excelência. Isto ocorre, raras vezes, principalmente em representaçóes em contextos rurais no final da década de 1970 e na de 1980. Será preciso esperar a segunda metade da década de 1990 para ver mulheres negras ocuparem uma posição de mulher desejável no contexto urbano. E, mesmo nesse caso - Fernanda Stalina Hurtado, filha de Jaime Hurtado (18/7/1991:38-40) e Mónica Chalá (16/11/1995) -, a visibilidade é criticada por muitos cidadãos brancos e branco-mestiços... (ver Rahier, 1998).

As representações de afro-equatorianos como perigosos criminosos são abundantes e começaram já nos primeiros números da revista. Em 1958, um artigo intitulado "Nas garras da erva mal-

Estudos Afro-Asiáticos, Ano 23, no 1, 2001, pp. 21-28 
dita" (7/1958:47-48, 85) marca o início dessa longa história de difamação "racial" ou étnica. As duas ilustrações de maconheiros são homens negros. Um deles se chama Santos Benigno Blackman Morales. O jornalista escreve a seu respeito: "Santos Benigno Blackmam Morales', tem uma contradição em seus nomes. Realmente: não deve ser nem muito benigno, nem muito santo, se está onde está. E isso de Blackman vem bem a calhar: sua cor é 'pura raça'. A África ruge”. No mês seguinte (8/1958:4-6, 71), outro artigo continua a saga: "5000 ladrōes em Guayaquil" é acompanhado pela foto de três homens negros na prisão. No ano seguinte, um artigo demonstra que essa imagem negativa do negro está tão enraizada no inconsciente coletivo branco e branco-mestiço que é utilizada para interpretar um acontecimento histórico do século XVI, no que hoje é chamado de "Dia da Província de Esmeraldas". O artigo tem por título "O negro que foi rei de Esmeraldas" (10/1959:72-74). O subtítulo principal diz: "De como os negros chegaram ao Equador. - Um rei sanguinário das selvas. - A Espanha age diplomaticamente". O texto que se segue relata, de maneira distorcida, a história do grupo de Sebastián Alonso de Illescas y de Antón, no século XVI, que foi salva do esquecimento pela crônica do padre Miguel Cabello Balboa (ver Cabello Balboa, 1965; Phelam, 1967; Rueda Novoa, 1990, 1992). É interessante notar que o jornalista jamais questiona a instituição da escravidão, sua desumanidade etc. Ao contrário, parece preocupado em pintar esses negros como selvagens que escaparam de sua condição "normal" ou "natural" de escravos, que são sanguinários, que agiram como animais e isto particularmente - diz o jornalista em um impulso paternalista - com os grupos indígenas que ocupavam a área aonde chegaram etc. $\mathrm{O}$ jornalista revisita a história para reforçar o estereótipo do negro delinqüente... Em nenhum momento quer festejar a valentia desses seres humanos que se rebelaram contra os seus opressores para recuperar sua dignidade e liberdade... O desenho que acompanha o artigo sugere a intenção do jornalista e do redator: mostra um negro musculoso com uma faca na mão, depois de matar um líder indígena que está no chão... Devemos recordar que a chegada do grupo de Sebastián Alonso de Illescas deu início ao que os historiadores chamaram de "a República de Zambos".

E os exemplos deste tipo de representações continuam ao longo da história da revista. Em 1961, a bestialidade de um prisioneiro negro é enfatizada pela seguinte legenda: "Se eu sair, tornarei a matar!" (7/1961:53-54). Esta história de difamação entusiástica

Estudos Afro-Asiáticos, Ano 23, no 1, 2001, pp. 22-28 
dos homens negros - que quando não os apresenta como delinqüentes "naturais ou animais selvagens que não podem controlar seus impulsos", apresenta-os como outro tipo de problema social: mães adolescentes, pobres sem escolaridade, "homens-rato" etc. chega até o presente. Em 1997, Vistazo festejou os seus quarenta anos de existência com um número especial. Nesse número, apresenta entrevistas de várias pessoas que completaram quarenta anos de idade em 1997. Assim, há entrevistas de um policial, de um médico, de um advogado, de uma secretária, de um pescador etc. $\mathrm{Na}$ página 118 do no 715 , de 5/6/1997, apresenta-se a entrevista e a fotografia de "O Delinqüente": um afro-esmeraldenho que, diz a legenda, vive há vinte anos na delinqüência e há dezesseis na prisão...

\section{Representações de Negros Norte-Americanos}

Os negros norte-americanos, ao contrário dos negros afro-equatorianos, não são representados como delinqüentes. Quer dizer, se de vez em quando se faz referência à delinqüência quando se escreve sobre eles, esta não aparece como sua primeira característica. Dentro da lógica do que chamo de "a ordem racial/espacial", os negros norte-americanos são muito mais associados à civilização ocidental do que os outros. Portanto, são considerados, nas páginas de Vistazo, como nas ruas e mentes do Equador, de maneira muito menos negativa, e em certos casos, positiva. Podem até ser pintados como povo que luta, com muito boas razões, contra injustiças desumanas, contra uma situação racista que é produto de uma longa história de discriminação baseada na cor da pele e na origem africana. Esta última representação é feita, sobretudo, nos números da revista das décadas de 1960 e 1970, quando se davam as agora famosas manifestações pela obtenção de uma legislação que assegurasse os "direitos civis" para todos os cidadãos, qualquer que fosse sua raça.

É interessante notar aqui que, embora os jornalistas e editores de Vistazo tenham a habilidade, sensibilidade e clarividência de não apenas relatar, mas também condenar o racismo da sociedade americana, permanecem totalmente cegos diante dos processos clara e dolorosamente racistas, bem como diante das práticas discriminatórias contra as populações negras equatorianas, desde o início da Colônia. O racismo é algo que se encontra "fora", não dentro do espaço nacional. Os afro-equatorianos são fundamen-

Estudos Afro-Asiáticos, Ano 23, no 1, 2001, pp. 23-28 
talmente delinqüentes urbanos, ou pequenos agricultores que não sabem como se superar em áreas rurais. Nada mais... O racismo é um mal que só existe no exterior.

Uma representação muito comum dos negros americanos em Vistazo é a que consiste em caracterizá-los como importantes esportistas, atletas e artistas de renome mundial. Até o final da década de 1970, a presença de imagens de negros americanos em Vistazo era muito limitada, apesar das reportagens sobre os acontecimentos dos direitos civis; no entanto, na década de 1980 sua presença aumenta consideravelmente através da cobertura dos sucessos de Michael Jackson e seus irmãos e irmãs; do Cosby show; do lançamento na televisão de "Raízes", escrito por Alex Haley; do ator negro de "Missão Impossível" etc. Nesses artigos, pode-se observar a surpresa e o fascínio dos jornalistas de Vistazo com o êxito econômico desses artistas negros dos EUA. Vários artigos breves, acompanhados de fotografias, são intitulados "Os negros mais ricos do mundo...", ou "Negros milionários" etc., expressando, assim, o quanto essas imagens foram surpreendentes sob uma perspectiva equatoriana.

\section{O Resto da Diáspora Africana}

Representações de negros que não sejam afro-equatorianos, africanos, ou negros americanos são relativamente raras ao longo da história de Vistazo. As poucas que pude encontrar no período indicado apontam, principalmente, para populaçóes afro-caribenhas e para o Brasil. Muito mais do que para os negros das outras categorias, e com exceção da república do Haiti (ver a seguir) e dos numerosos artigos sobre Pelé (o rei brasileiro do futebol), as representações de desejáveis mulheres negras são aqui dominantes, e isto desde os primeiros anos da revista. No entanto, sobretudo no que diz respeito a populações caribenhas, essas representações também são marcadas por referências constantes à África selvagem, com seus rituais misteriosos e estranhos, que definitivamente os marcam como exóticos...

Em 1958, um artigo intitulado "Calipso em Guayaquil" ( $n^{\circ}$ 16, 9/1958:71) está acompanhado por duas fotografias: no centro da primeira aparece uma atraente mulher negra dançando com as pernas descobertas e movendo sensualmente a cintura entre dois homens negros que, de joelhos, abrem os braços como para proclamar e festejar sua beleza. Na segunda, há três homens negros vesti-

Estudos Afro-Asiáticos, Ano 23, no 1, 2001, pp. 24-28 
dos somente de pedaços de pano na cintura, imitando pele de tigre, dançando com lanças nas mãos. O jornalista, que é correspondente itinerante do Vistazo em Lima, escreve:

Vi os negros do "Calipso de Trinidad" aqui em Lima estrearem no melhor teatro da cidade, o "City Hall", e depois tornei a aplaudi-los na "Embassy", a melhor boite de Lima. São maravilhosos; quis entrevistá-los para Vistazo e, com um intérprete, já que só falam inglês, além do seu dialeto do interior, o que me transportava aos anos da minha juventude, quando me emocionavam os filmes de Tarzá, rodeado de negros e mais negros, consegui uma curta conversa com eles. O que faz de líder me disse: "O nosso espetáculo nasceu como uma resposta à proibição policial inglesa contra nossas tradicionais bandas africanas. Despertamos curiosidade e mostramos o nosso folclore, creio que de maneira demasiado crua".

Outro artigo, intitulado "Com o diabo no corpo" (no 443, 7/2/1986:42-44), reforça essa imagem da mulher afro-caribenha como mulher quente capaz das mais extravagantes habilidades sexuais: a fotografia principal do artigo ocupa uma página inteira e mostra uma mulher negra de frente, que dança esfregando o traseiro contra a pélvis de seu colega bailarino, que podemos ver dançando atrás dela. A fotografia foi tirada durante um carnaval em Trinidad. Entre outros artigos e fotografias que apontam na mesma direção, pode-se destacar também um texto publicado em 5/9/1986, dedicado à Miss Brasil 1986. Às vezes o jornalista chama-a de "a bela mulata". Outras vezes utiliza frases dramáticas como "o sonho da Gata Borralheira negra" etc. Muitas das fotografias mostram-na em traje de banho. A última foto tem a legenda: "Gesto de sonho, magia e paixões transbordantes. Miss Brasil é um poema mulato".

Não poderia terminar esta parte sem comentar duas fotografias que me surpreenderam por serem bastante únicas dentro do conjunto de fotografias que compilei. A primeira foi tirada no Brasil, durante o carnaval de fevereiro de 1959 , e publicada no no 22 , de março do mesmo ano. Acompanha um artigo sobre o carnaval do Rio que relata vários eventos, entre os quais a tentativa de um grupo de admiradores de desnudar Jane Mansfield. Nessa fotografia pode-se ver um homem negro beijando a boca uma mulher branca ou branco-mestiça, que com algo de ternura corresponde com afeto acariciando seu torso. Essa fotografia encaixa-se, é claro, na reputação do carnaval do Rio, durante o qual tudo poderia acontecer. Sem dúvida, é pela sensação que cria na sociedade equatoriana da época que foi escolhida pelo jornalista e pelos editores

Estudos Afro-Asiáticos, Ano 23, no 1, 2001, pp. 25-28 
da revista. A legenda impressa abaixo da fotografia diz: "Um exemplo para o povo de Little Rock [nos EUA, onde acabava de ocorrer um fato racista], aqui um preto beija uma linda garota. A alegria dos cariocas os faz esquecer todo tipo de preconceitos...". A situação inversa, quer dizer, um homem branco ou branco-mestiço beijando uma mulher negra, seria certamente menos sensacional. A história de relações raciais em contextos colonial e neocolonial nas Américas, assim como na África, está cheia desses casos que expressam apenas o poder das elites socioeconômicas e políticas. Para continuar com o tema, a segunda fotografia segue a ordem "natural" das coisas e, portanto, é menos subversiva que a precedente: representa um homem branco e vestido (um sacerdote anglicano) dominando - pelo menos com o olhar - uma mulher negra nua que tem apenas um pedacinho de pano sobre as coxas. O leitor pode vê-la de costas com o traseiro descoberto. $\mathrm{O}$ artigo intitula-se: "O sacerdote que pinta nus" e conta a história de um sacerdote anglicano que tem paixão por pintar mulheres nuas.

Nesta categoria de artigos e fotografias sobre o "resto da diáspora africana”, destacam-se as referências ao Haiti. O Haiti é fundamentalmente representado de maneira muito negativa em Vistazo. Assim como o fascínio que a revista teve pelos ditadores africanos Idi Amin Dada e Jean Bédel Bokassa, a ditadura dos Duvaliers inspirou sete artigos na revista. Cada um deles enfatiza os aspectos sanguinários dos regimes de Papa e Baby Doc, e seus gastos extravagantes contrastando com a pobreza do povo haitiano. Nisto a imagem do Haiti traça um paralelo na questão coincidente com a imagem da África. Particularmente quando se consideram as reportagens sobre as tradiçôes religiosas da ilha: o vodu. Este último não é representado como uma religião respeitável como outras, com uma cosmovisão própria, um sistema de rituais específicos, um panteão, uma hierarquia religiosa etc., mas como uma prática selvagem de magia negra. Este preconceito ou imagem estereotipada não existe apenas no Equador, é claro. Vários artigos têm títulos dramáticos que denotam esta visão negativa do vodu, e, com ela, também da população do Haiti: "O país dos mortos que caminham" (no 137, 10/1968:49-52); "Os vampiros humanos do Haiti" (no 162, 11/1970:88-92); "Duvalier: fim de um império de sangue" (8/2/1985:14-17), que contém o subtítulo "Papa Doc' Duvalier iniciou há 28 anos no Haiti uma ditadura baseada no terror e na magia negra..."

Estudos Afro-Asiáticos, Ano 23, no 1, 2001, pp. 26-28 
Mãe, o Que Será que o Negro Quer?

\section{Conclusões}

Assim como o que se pode encontrar profundamente ancorado no inconsciente coletivo branco e branco-mestiço equatoriano, representações das pessoas negras foram construídas na Vista$z o$, ao longo de sua história, como para situá-las de maneira definitiva como seres marginais em tudo o que se entende por "civilização", "nação" e "cultura nacional". Entre as várias categorias de negros que se encontram em Vistazo e com as quais trabalhei, observa-se que os afro-equatorianos são representados como os mais negativos de todos, depois dos africanos: não são ricos e civilizados, ou artistas de reputação internacional como os gringos negros; não são sensual e sexualmente tão atraentes (antes da década de 1990) como os negros - ou, antes, as negras - caribenhas e brasileiras. Quando estão em suas zonas rurais (a província de Esmeraldas e o Vale do Chota), são pintados como africanos (ver, por exemplo, o artigo "Um canto da África nos Andes", na Vistazo de 22/6/1984:90-96), com tudo que isso contém de negativo. Em áreas urbanas, em compensação, tornam-se perigosos, selvagens e sanguinários delinqüentes, também parecidos com africanos, mas com o aspecto de seu significado que evoca a violência ("A África Ruge"). Em suma, as representações de afro-equatorianos marcam-nos como seres marginais ao projeto nacional das elites equatorianas. Essa marginalidade não é resultado do número relativo de negros com que conta o Equador, como foi dito em várias ocasióes por intelectuais e políticos brancos e branco-mestiços. Essa marginalidade é a expressão do fato de que as pessoas negras cumprem o papel de último Outro nos imaginários de identidade nacional. $\mathrm{Na}$ lógica da ideologia hegemônica de identidade nacional que define a "equatorianeidade", os negros constituem o que ninguém (os brancos e branco-mestiços) quer ser. O ser negro é definido como o contrário de "ser civilizado". Os negros não podem encarnar o que se proclama como os ideais da nacionalidade. Cumprem o papel de Outro, tanto dentro das fronteiras nacionais como fora delas. Nem são incluídos nos mitos da equatorianeidade quando se fala de "branqueamento". Este último é um processo que leva à "nacionalidade" (imaginada pelas elites) reservada aos indígenas. Esta qualidade negativa de "último Outro" é até reproduzida por muitos intelectuais equatorianos - brancos e branco-mestiços - que nem se dão ao trabalho de incluí-los em suas pesquisas e outras preocupaçóes.

Estudos Afro-Asiáticos, Ano 23, no 1, 2001, pp. 27-28 
Jean Rahier

Esta marginalidade dos negros equatorianos de hoje não é mais do que a continuação de uma longa história de discriminação que começou durante a Colônia e não só foi reproduzida, mas também reforçada através das décadas, nos vários meios de comunicação, e no "senso comum nacional".

\section{Notas}

1. Todas as traduções deste artigo são de minha autoria.

2. Tenho o projeto de chegar até o ano 1998.

3. Para um estudo similar conduzido em outro contexto nacional, ver Lutz (1993).

4. Trata-se de uma pesquisa em curso. Planejo estender esta lista em um futuro próximo.

5. Na história de Vistazo, mais de dez artigos foram dedicados ao ditador Idi Amim Dada, como se ele fosse um emblema, uma boa ilustração do que é a África...

6. A questão de gênero e raça em Vistazo merece um estudo muito mais detalhado do que o presente.

Estudos Afro-Asiáticos, Ano 23, no 1, 2001, pp. 28-28 